\title{
Adsorption of Diclofenac from Aqueous Solution Using Highly Meso porous Carbon
}

\author{
Ebtsam S. Hamza ${ }^{a}$, Nadia A. Youssef ${ }^{b, *}$, Seham A. Shaban ${ }^{c}$ \\ a, b Chemistry Department, Faculty of Women for Arts, Science and Education, Ain-Shams University, \\ Cairo, Egypt. \\ ${ }^{c}$ Egyptian Petroleum Research Institute (EPRI), Cairo, Egypt.
}

\begin{abstract}
Synthetics of mesoporous carbon (MC) from biomass including sucrose was used as the carbon resource, and eutectic salt $(\mathrm{KCl} / \mathrm{NaCl})$ as the porogen agent for the preparation of $\mathrm{S}-\mathrm{MC}$ (sucrose mesopores carbons). The resultant samples were examined by means of different techniques, including thermal analysis (TGA), FTIR, transmitted electron microscopy (TEM), X-ray diffraction (XRD) and BET measurements.

Investigate the efficiency of adsorption of diclofenac by highly mesopores carbons using Ultraviolet-Visible spectroscopy. The final concentrations of diclofenac were measured using Ultraviolet-Visible spectroscopy at different conditions ( $\mathrm{pH}$, contact time, temperature, weight of adsorbate, weight of adsorbent).
\end{abstract}

Key words; diclofenac, sucrose, meso porous carbon, UV-spectroscopy.

\section{INTRODUCTION}

Mesoporous carbon (MC) has attracted increasing attention, due to its unique properties, such as extraordinary chemical, mechanical, and thermal stability, and wide abundance in nature [1]. Nowadays, the widespread applications of MCs in various areas such as supercapacitors, chemical sensors, catalyst supports, fuel cells and separation sorbents, have encouraged researchers to synthesize porous carbons with high mesoporous volume proportions and a high specific surface area (SSA) [2-7]. Therefore, it is important to develop reliable methods for the preparation of MCs with controllable porosity, together with high SSA and large pore volume.

In the past decades, numerous carbon resources, such as fossil-based hydrocarbons (e.g., bituminous coal, lignite), biomass (e.g., sucrose, glucose, cellulose, lignin and wood), and polymers, have been utilized for the preparation of MCs. In particular, biomass including cellulose, lignin, and their platform molecules, provides an abundant feedstock for the

*Corresponding author: Nadia A. Youssef, Chemistry Department, Faculty of Women for Arts, Science and Education, Ain-Shams University, Cairo, Egypt.

E-mail: nnaadd@ @ot mail.com 
preparation of carbon materials [8-22]. Due to the presence of plentiful oxygen in the biomass resource, the carbons derived from biomass generally contain oxygen-containing groups, which may provide the carbons with specifies functions. Thus, the preparation of porous carbons from biomass has attracted significant attention.

For the preparation of porous carbon materials, porogens, such as surfactants [9, $\mathbf{2 3 , 2 4}$ salts [25-29], and their mixtures [30, 31], are generally required. sodium chloride $(\mathrm{NaCl})$ is one of the porogens most widely used in the preparation of activated carbon (AC) from biomass (e.g., olive stones, oil palm shells, and kraft lignin), and can result in porous carbon materials with high SSAs (e.g., 400-2170 $\mathrm{m}^{2} \mathrm{~g}-1$ ) and high carbon yields [15,32-36]. However, the proportions of mesopores in the resultant ACs are generally low (5 - 40\%) $[9,23,32,37]$. Recently, Antonietti and coworkers utilized eutectic salt composed of $\mathrm{ZnCl}_{2}$ and chloride salts as a porogen to regulate the pore diameters of the carbon materials derived from ionic liquids [30]. They found that the combination of $\mathrm{ZnCl}_{2}$ with different salts could tune the pore size of the resultant carbons. For example, $\mathrm{LiCl} / \mathrm{ZnCl}_{2}$ resulted in microporous carbons; $\mathrm{NaCl} / \mathrm{ZnCl}_{2}$ afforded microporous and small mesoporous carbons, while $\mathrm{KCl} / \mathrm{ZnCl}_{2}$ mainly resulted in MCs with large mesopores. The $\mathrm{ZnCl}_{2}$-based eutectic salt showed promising potential for the preparation of MCs. However, it has seldom been applied in the preparation of MCs from biomass carbonization [31, 38].

In this work, biomass sucrose was used as the carbon resource, and $\mathrm{KCl} / \mathrm{ZnCl}_{2}$ mixture used as the porogen agent for the preparation of S-MC (sucrose mesopores carbons) [30]. The porous carbons were obtained via heating program, and the final calcination temperature. The resultant sample were examined by means of different techniques, including FTIR, scanning electron microscopy (SEM), $\mathrm{N}_{2}$ sorption, and X-ray diffraction (XRD).

\section{EXPERIMENTAL}

\subsection{Materials}

Sucrose, was purchased from Alfa Chemical Reagent. $\mathrm{KCl}$ and $\mathrm{ZnCl} 2$ (99\%) were acquired from Aldrich Chemical Reagent. All chemicals were used without further purification.

Sodium diclofenac DCF (Sodium 2-[2-[(2,6-dichlorophenyl) amino] phenyl] acetate) was purchased from Acros. DCF is a non-steroidal anti-inflammatory drug with molecular formula of $\mathrm{C}_{14} \mathrm{H}_{10} \mathrm{Cl}_{2} \mathrm{NNaO}_{2}$, melting point of $283-285^{\circ} \mathrm{C}$, water solubility of $0.00482 \mathrm{mg} / \mathrm{mL}$ 
and formula mass of $318.13 \mathrm{~g} / \mathrm{mol}$. The maximum wavelength of DCF is $276 \mathrm{~nm}$. The structure of DCF is represented in Fig. 1.<smiles>O=C(O)Cc1ccccc1Nc1c(Cl)cccc1Cl</smiles>

Fig. 1. Chemical structure of diclofenac .

\subsection{Synthesis of adsorbents materials}

We take broadly utilized and minimal effort biomass, sucrose as the model substrates and the materials was blended by the announced method with a few alterations [24]. In a common amalgamation, $1.0 \mathrm{~g}$ of sucrose, $4.248 \mathrm{~g}$ of $\mathrm{KCl}$ and $7.76 \mathrm{~g}$ of $\mathrm{ZnCl} 2$ were disolved in $50 \mathrm{~mL}$ of distilled water with magnetic stirring at room temperature for 24 hours to get a homogeneous solution. Under vacuum distillation, uniform powder was acquired. At that point the uniform powder was annealed under $\mathrm{N}_{2}$ atmosphere at $800^{\circ} \mathrm{C}$ for 6 hours.

At the end, the strong item was gathered with a rotator and washed a few times with distillation water until there is no chloride particle in the upper arrangement. S-MC (sucrose mesopores carbons) was gotten after the strong item was additionally dried at $80^{\circ} \mathrm{C}$ for $12 \mathrm{~h}$ in a stove. Schema 1 demonstrates the techniques for the planning of S-MC.

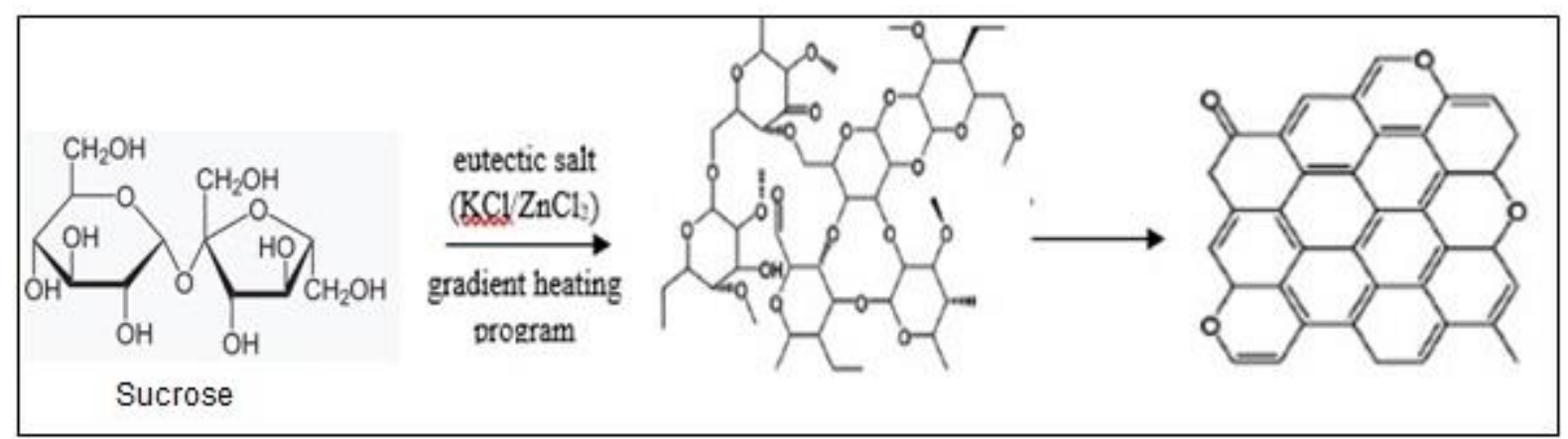

Schema 1: demonstrates the techniques for the planning of S-MC. 


\subsection{Adsorbent characterization}

Powder X-ray diffraction (P-XRD) patterns were recorded on a Bruker AXS D8ADVANCE diffractometer at the $2 \theta$ range of $5-90^{\circ}$ using a filtered $\mathrm{CuK} \alpha$ radiation source $(\lambda=1.54056 \AA)$.

The texture properties of the obtained $\mathbf{S}-\mathbf{M C}$ were estimated from $\mathrm{N}_{2}$ gas adsorption and desorption analysis measured at liquid nitrogen temperature $\left(-196^{\circ} \mathrm{C}\right)$ using a Quantachrome Nova $3200 \mathrm{~S}$ apparatus. Prior to analysis, the sample was outgassed for $12 \mathrm{~h}$ at $250{ }^{\circ} \mathrm{C}$ under $\mathrm{N}_{2}$ atmosphere in order to remove moisture from the adsorbent surface. The specific surface area was calculated using this method and the total pore volume was computed from the amount of adsorbed $\mathrm{N}_{2}$ at $\mathrm{P} / \mathrm{P}^{\mathrm{o}}$ of 0.95 . The pore size distribution curve of S-MC was also calculated.

HR-TEM imaging was performed on a JEOL JEM-2100F instrument operated at $200 \mathrm{kV}$. Fourier transform infrared (FT-IR) spectra were obtained on an ATI unicam (Mattson 936) Bench Top Spectrometer with pressed $\mathrm{KBr}$ pellets in the range of $4000-400 \mathrm{~cm}^{-1}$.

\subsection{Adsorption experiments}

In a typical sorption run, known weights of S-MC $(0.1-0.75 \mathrm{~g} / \mathrm{l})$ were placed in a series of $100 \mathrm{ml}$ glass vials holding $50 \mathrm{ml}$ of DCF (20-70 ppm) solutions and the resultant mixtures were allowed to shake in a thermostatic shaker incubator at $150 \mathrm{rpm}$ at room temperature. S-MC was dried at $150{ }^{\circ} \mathrm{C}$ overnight to remove moisture before being used in the sorption experiments. After a required time intervals, $3 \mathrm{ml}$ aliquots were taken from the vials, centrifuged to separate adsorbent particles and analyzed for their residual DFC concentration using a UV-vis spectrophotometer (JASCO, V-750 UV-visible Spectrophotometer). Every experiment was replicated three times and the mean values were adopted.

The percentage removal of DCF $\left(\mathrm{R}_{\mathrm{e}}\right)$ and the amounts of DFC adsorbed per unit mass of S-MC at time $\mathrm{t}\left(q_{\mathrm{t}}, \mathrm{mg} / \mathrm{g}\right)$ and at equilibrium $\left(q_{\mathrm{e}}, \mathrm{mg} / \mathrm{g}\right)$ were obtained by the following equations:

$$
\begin{aligned}
R_{e} & =\frac{C_{\mathrm{o}}-C_{e}}{C_{\mathrm{o}}} \times 100 \\
q_{t} & =\frac{\left(C_{\mathrm{o}}-C_{t}\right) V}{m}
\end{aligned}
$$




$$
q_{e}=\frac{\left(C_{\mathbf{o}}-C_{e}\right) V}{m}
$$

Where $\mathrm{C}_{\mathrm{o}}$ and $\mathrm{C}_{\mathrm{e}}(\mathrm{mg} / \mathrm{l})$ are the initial and the equilibrium concentrations of DCF, respectively, $\mathrm{C}_{\mathrm{t}}(\mathrm{mg} / \mathrm{l})$ is the concentration of DCF at time $\mathrm{t}, \mathrm{V}(\mathrm{l})$ is the volume of the solution and $\mathrm{m}(\mathrm{g})$ is the adsorbent weight.

\section{RESULTS \& DISCUSSION}

\subsection{Adsorption Characterization}

In this work, various carbon samples were prepared via hydrothermal reaction between sucrose as carbon resources and porogen agent (eutectic salt $\left(\mathrm{KCl} / \mathrm{ZnCl}_{2}\right)$ ) at final calcination temperature.

The sample prepared using sucrose as the carbon resource was examined by FT-IR Fig. 2. Compared to the spectrum of pristine sucrose, the spectrum of resultant sample shows declined corresponding peaks, accompanied with the appearance of new bands around 1623 $\mathrm{cm}^{-1}$ and $1690 \mathrm{~cm}^{-1}$.

In the spectrum of sample S-MC, which was prepared by program calcination temperature of $800^{\circ} \mathrm{C}$, the bands around $3430 \mathrm{~cm}^{-1}$ was assigned to the stretching vibration of the $\mathrm{O}-\mathrm{H}$ bond, and those around $2920 \mathrm{~cm}^{-1}$ and $1046 \mathrm{~cm}^{-1}$ corresponded to $\mathrm{C}-\mathrm{H}$ vibrations. These bands became wider and less intense compared to those of sucrose, suggesting that most of the $\mathrm{O}-\mathrm{H}$ and $\mathrm{C}-\mathrm{H}$ bonds from sucrose had disappeared in this sample.

Moreover, the band at $1097 \mathrm{~cm}^{-1}$ in the FT-IR spectrum of sucrose corresponding to the $\mathrm{C}-\mathrm{O}$ bond vibration almost disappeared in the spectrum of sample $\mathbf{S}-\mathbf{M C}$, indicating the cleavage of the $\mathrm{C}-\mathrm{O}$ bond from the sucrose molecule. Notably, the new bands appearing at $1623 \mathrm{~cm}^{-1}$ and $1690 \mathrm{~cm}^{-1}$ corresponded to $\mathrm{C}=\mathrm{C}$ and $\mathrm{C}=\mathrm{O}$ vibrations, respectively. This indicated that sucrose was converted to $\mathrm{C}=\mathrm{O}$ containing compounds catalyzed by $\mathrm{ES}$, $[19,20,41]$ identical to the TGA results [39]. 
J. Sci. Res. Sci., Vol. (37), 2020

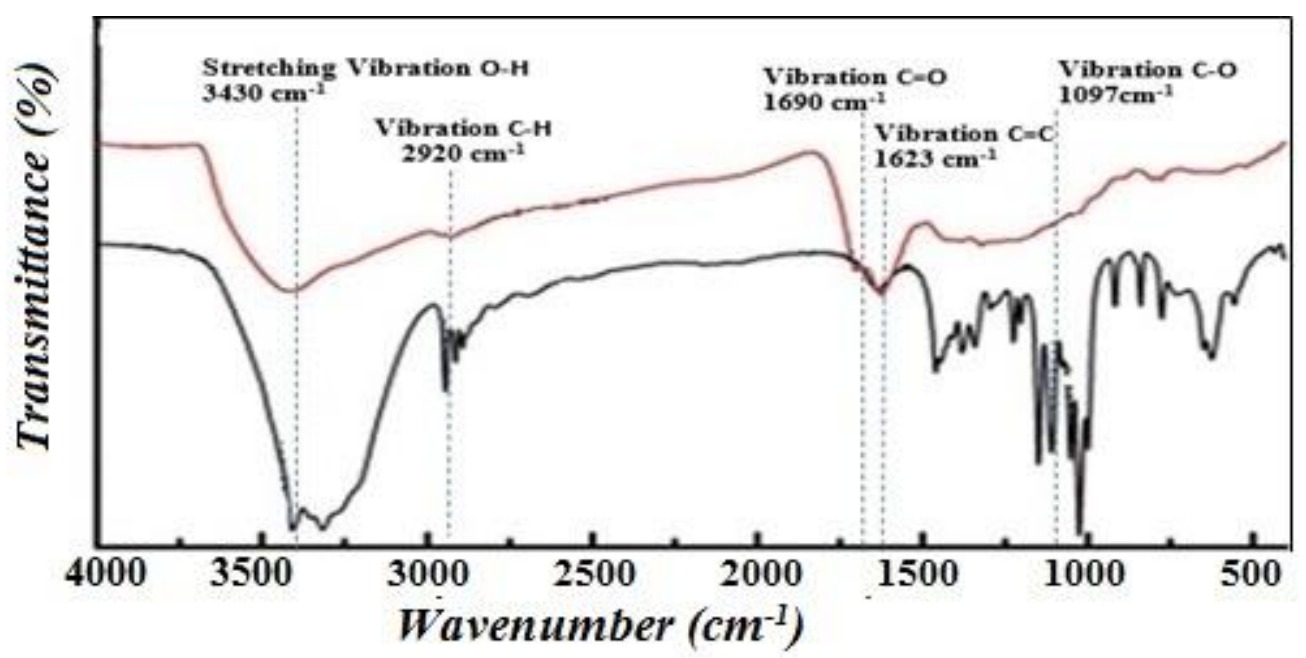

Fig. 2. FT-IR spectra of sucrose and of the resultant S- MC sample.

The morphology and structure of the samples prepared at the calcination temperature of $800^{\circ} \mathrm{C}$ was examined. Fig. 3. S-MC appeared to be composed of primary rough carbon particles with size around $10 \mathrm{~nm}$, which were aggregated to give a porous and aerogel-like structure. In contrast, the morphology of $\mathbf{S}-\mathbf{M C}$ suggest that the porogen played an important role in controlling the morphology of the resultant samples.

Table 1 : Textural properties of $\mathbf{S}-\mathbf{M C}$

\begin{tabular}{|l|l|}
\hline Total surface area, $\mathbf{~ m} 2 / \mathbf{g}$ & $\mathbf{5 7 5 . 5 3}$ \\
\hline Micropores area, $\mathrm{m}^{2} / \mathrm{g}$ & 214.95 \\
\hline Mesopores area, $\mathrm{m}^{2} / \mathrm{g}$ & 360.58 \\
\hline Micropores pore volume, $\mathbf{c m}^{\mathbf{3}} / \mathbf{g}$ & $\mathbf{0 . 1 5} \mathbf{~ m m}$ \\
\hline Mesopores pore volume, $\mathbf{c m}^{\mathbf{3}} / \mathbf{g}$ & $\mathbf{0 . 4 8}$ \\
\hline Micropores size, $\mathbf{n m}$ & $\mathbf{1 . 9}$ \\
\hline Mesopores size, $\mathbf{n m}$ & $\mathbf{3 . 6 7}$ \\
\hline
\end{tabular}




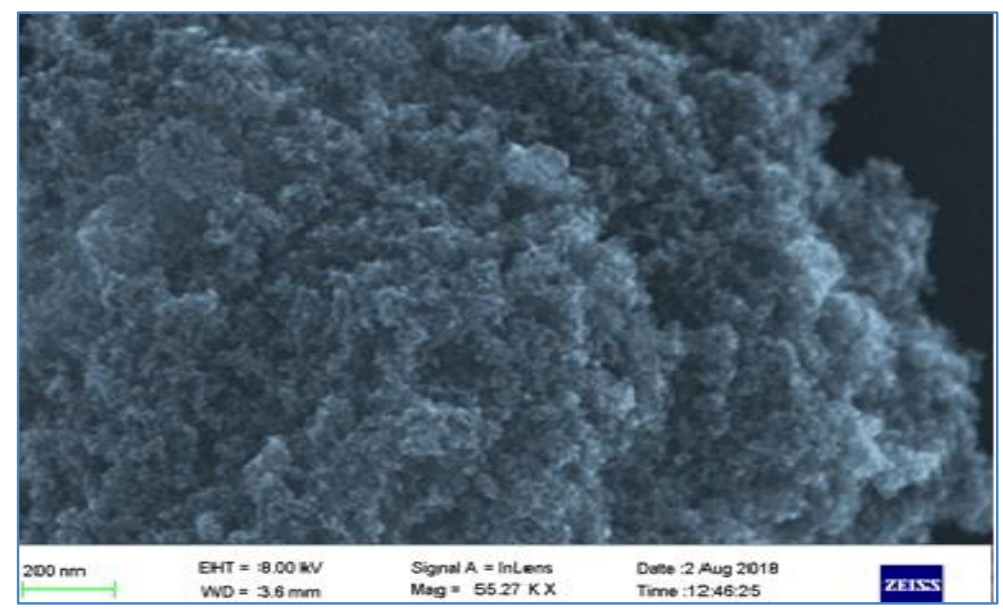

Fig. 3: HR-TEM image of the synthesized S-MC

Figure 4.a shows the curve of nitrogen adsorption-desorption isotherm of the S-MC catalyst obtained and pore size distribution. The curve shows a type IV isotherm that is characteristic of mesopore solids and type hysteresis $\mathrm{H}_{2}$ that is characteristic of pores with irregular morphology $[34,35]$.

This was further ascertained by the pore-size distribution plot Fig.4.b which obviously demonstrated the attendance of micropores with an average size of approximately $1.9 \mathrm{~nm}$ and mesopores with an average size of approximately $3.67 \mathrm{~nm}$, respectively. S-MC showed a large surface area of $575.53 \mathrm{~m}^{2} / \mathrm{g}$ with micro- and mesoporous surface areas of $360.58 \mathrm{~m}^{2} / \mathrm{g}$ and $214.95 \mathrm{~m}^{2} / \mathrm{g}$, respectively. The total pore volume of the sample was found to be $1.3 \mathrm{~cm}^{3} / \mathrm{g}$ in which the micro- and mesoporous volumes were $0.15 \mathrm{~cm}^{3} / \mathrm{g}$ and $0.48 \mathrm{~cm}^{3} / \mathrm{g}$, respectively. That is, the vast majority of the total surface area and pore volume of $\mathbf{S}-\mathbf{M C}$ was emanated from mesopores. Such mesoporous structure would be suitable for adsorption purposes in terms of improved accessibility of the adsorbent to the active binding centers within the porous structure of $\mathbf{S - M C}$ as well as high diffusion rates table 1. 
J. Sci. Res. Sci., Vol. (37), 2020
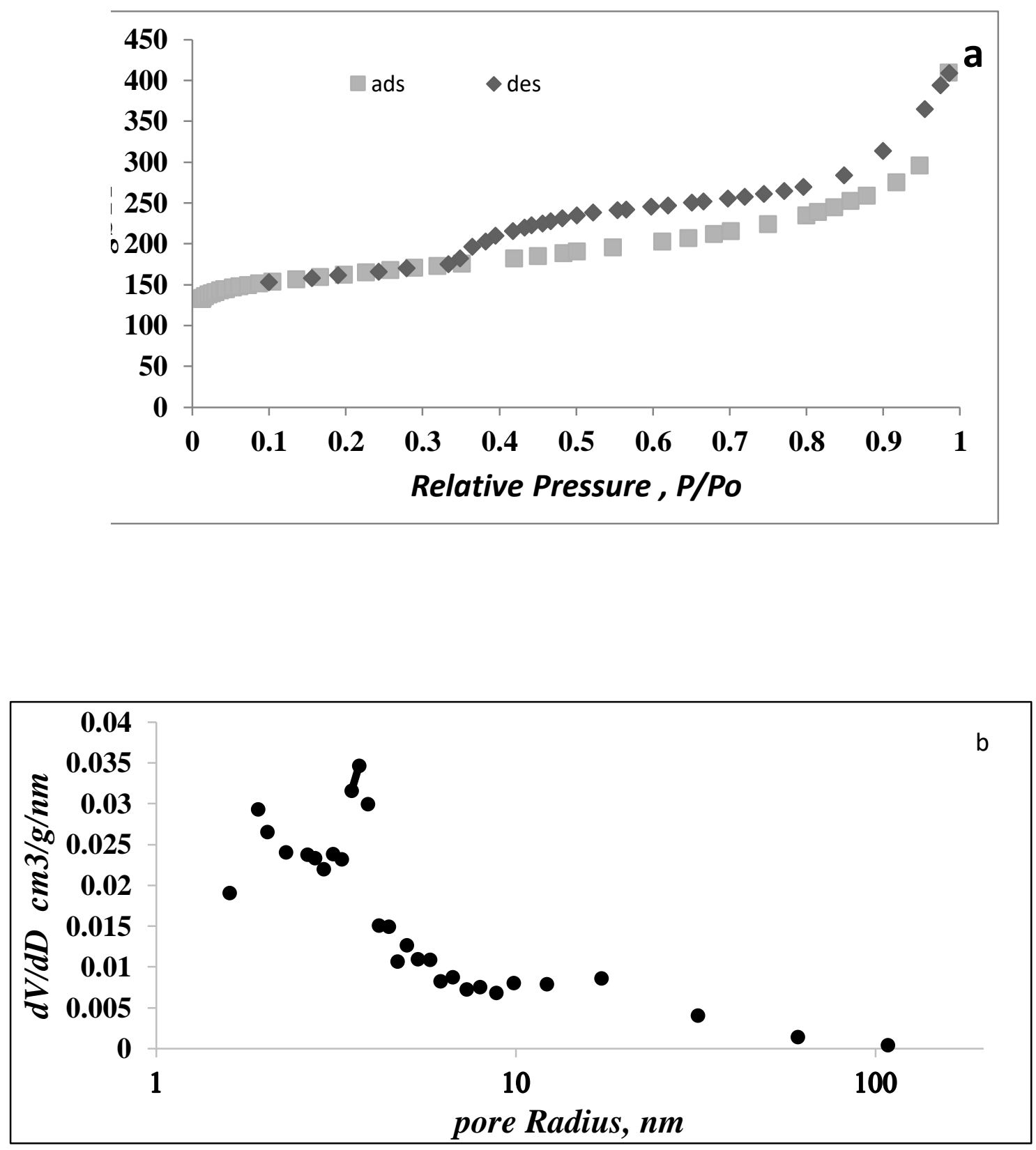

Fig. 4: (a) $\mathrm{N}_{2}$-adsorption isotherm, (b) BJH curve of the synthesized S-MC

\subsection{Adsorption of diclofenac sodium on S-MC}

UV-Vis spectrophotometry was chosen and preferred over many other methods. That is due to its low pollution effects, simplicity, speed and suitability to indicate the kinetic change of the diclofenac sodium concentration. A typical calibration curve for diclofenac sodium at $276 \mathrm{~nm}$. 


\subsection{Effect of contact time}

The effect of contact time on removal percentage of diclofenac sodium is shown in Fig. 5. The adsorbed amount of DCF onto S-MC increases with the increase of contact time, as shown in Fig. 5, and the DCF adsorption reached equilibrium in about $60 \mathrm{~min}$. Adsorption capacity for DCF showed a rapid increase in adsorption amount during the first $20 \mathrm{~min}$. This fast adsorption capacity at the initial stage indicated higher driving force that made fast transfer of DCF to the surface of S-MC particles. From Fig. 5 the\% removal of DCF using SMC was $90.6 \%$.

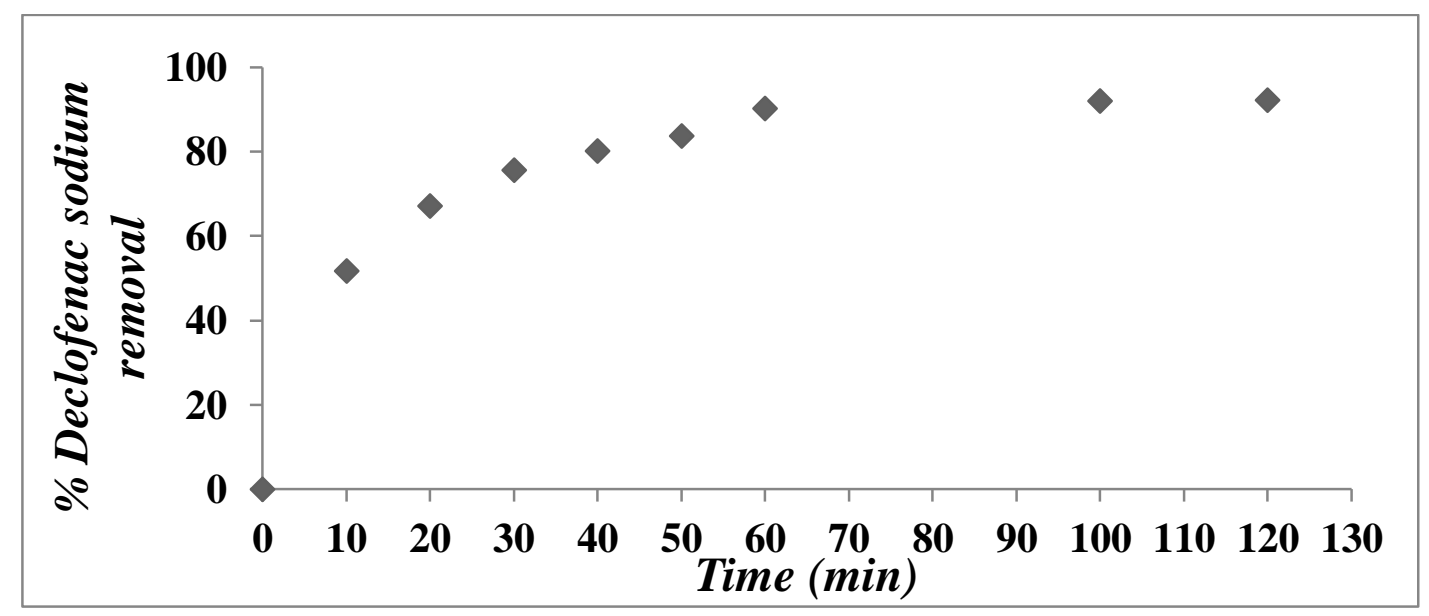

Fig. 5: Effect of contact time on DCF removal by S-MC ( $\mathrm{pH} 2$, room temp., Adsorbent dosage $0.5 \mathrm{~g}$, initial conc. $50 \mathrm{mg} / \mathrm{l}$ ).

\subsection{Effect of PH}

The variation of adsorption onto S-MC was investigated in the $\mathrm{pH}$ range 2-8 using hydrochloric acid and sodium hydroxide to control $\mathrm{pH}$. The effect of $\mathrm{pH}$ on diclofenac sodium removal was studied, using $0.5 \mathrm{~g} / \mathrm{l}$ of $\mathrm{S}-\mathrm{MC}$ at an adsorption time of $60 \mathrm{~min}$ to reach equilibrium, Fig. 6 summarizes these results. For each adsorbent, the optimal $\mathrm{pH}$ for the adsorption of diclofenac sodium was 2 , this result indicated a $\mathrm{pH}$ less than the $\mathrm{pKa}$ of this pharmaceutical ( $\mathrm{pKa}=4.20)$, as DCF is present in its neutral form, and its solubility in water decreases. So as $\mathrm{pH}$ decreases the 'Van der Waal' interaction between DCF and the adsorbent surface increased by physical adsorption process. 


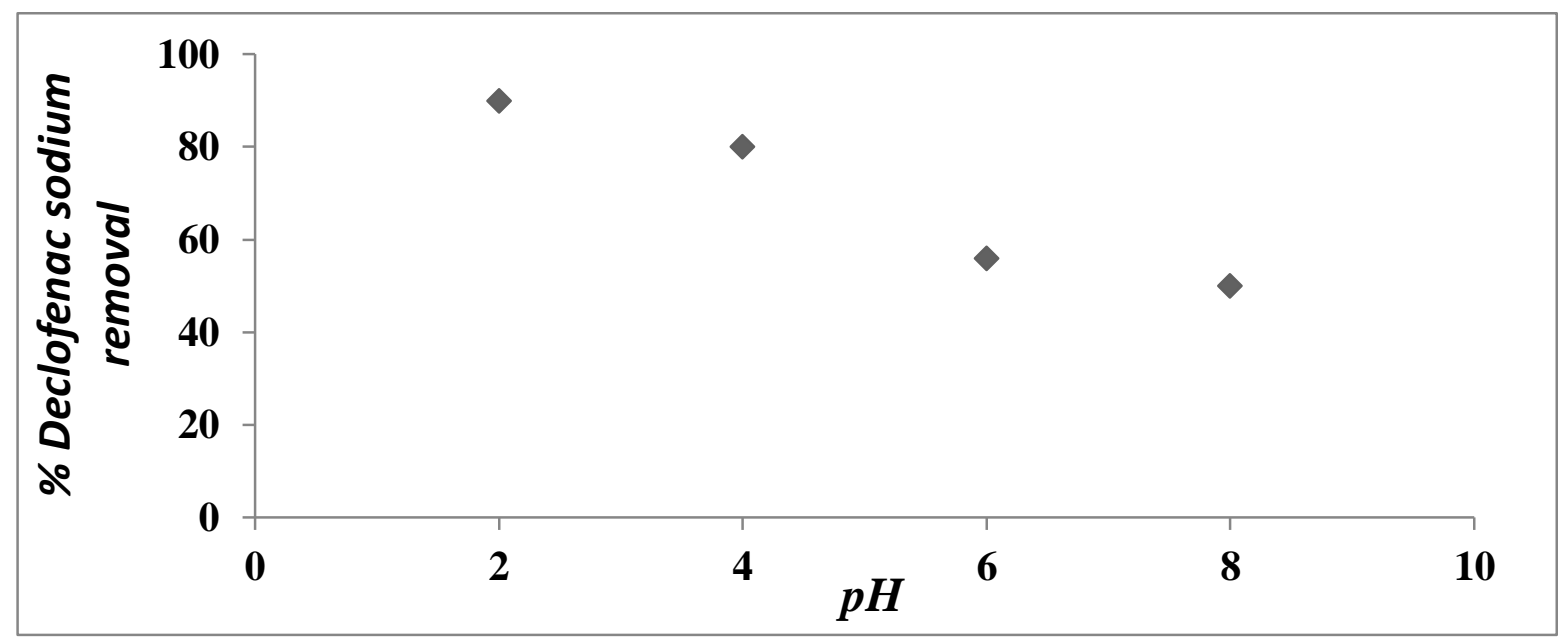

Fig. 6: Effect of $\mathrm{pH}$ on DCF removal by S-MC

(room temp., $60 \mathrm{~min}$, adsorbent dosage $0.5 \mathrm{~g} / \mathrm{l}$, initial conc. $50 \mathrm{mg} / \mathrm{l}$ ).

\section{5. Effect of temperature}

The effect of temperature on adsorption onto S-MC was investigated in the range of 25$50^{\circ} \mathrm{C}$. The results are shown in Fig. 7. In this figure, diclofenac sodium adsorption decreased with increasing temperature. The highest percentage of adsorption performance was at $25^{\circ} \mathrm{C}$ (room temperature) which reached $90.2 \%$ by S-MC. Increasing temperature will cause an increase in solubility of water and this will decrease the adsorption process and decrease the attraction forces between DCF and the pharmaceuticals.

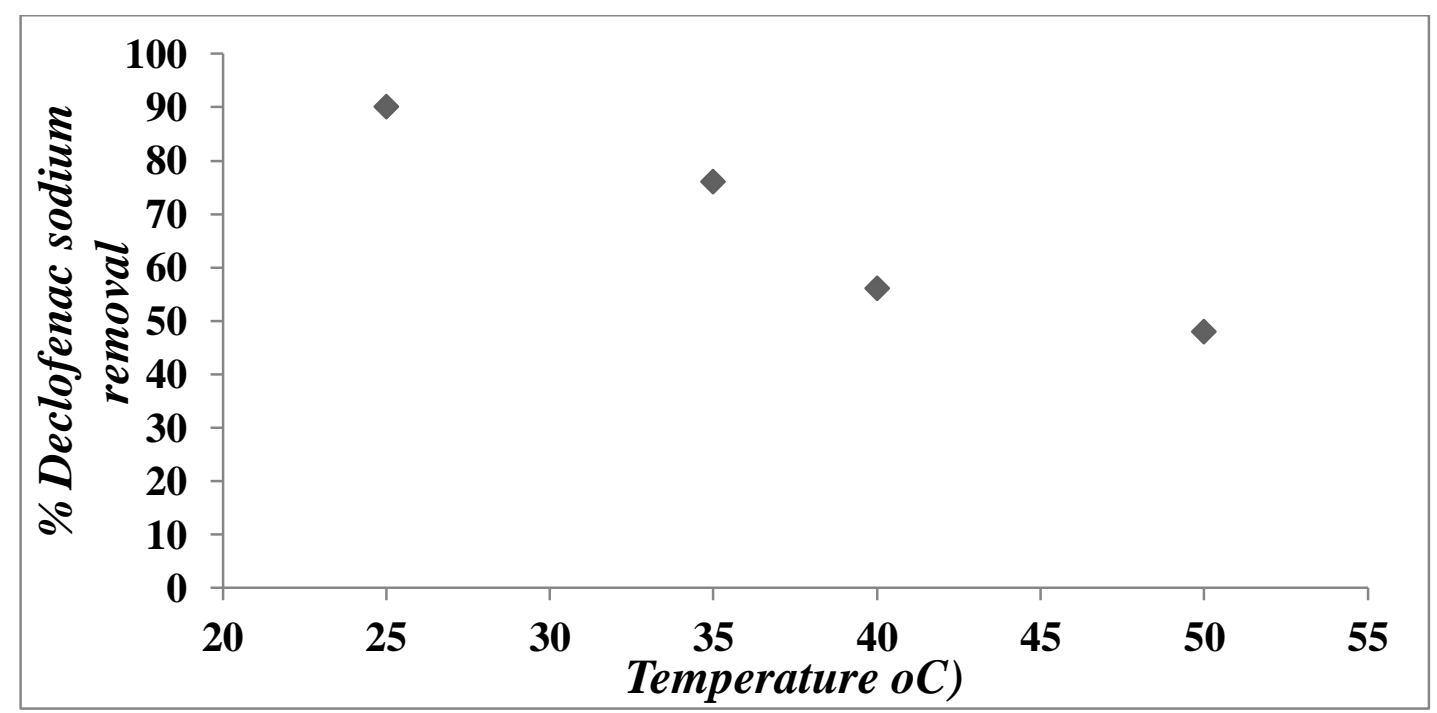

Fig. 7: Effect of temperature on DCF removal by S-MC 
(at; $\mathrm{pH}$ 2, $60 \mathrm{~min}$, adsorbent dosage $0.5 \mathrm{~g} / \mathrm{l}$, initial conc. $50 \mathrm{mg} / \mathrm{l}$ ).

\subsection{Effect of adsorbent dosage}

The effect of S-MC dosage on diclofenac sodium removal was studied using $0.1-0.75 \mathrm{~g} / 1$ adsorbent dosage at an adsorption time of $60 \mathrm{~min}$ to reach equilibrium. The results are summarized in Fig. 8.

The percent of DCF removal increased by increasing dosage. Adsorption increases up to $94 \%$ with an adsorbent amount of $0.75 \mathrm{~g} / \mathrm{l}$ of S-MC, because increasing adsorbent weight at fixed DCF concentration provided more available adsorption sites and thus increased the extent of DCF removal.

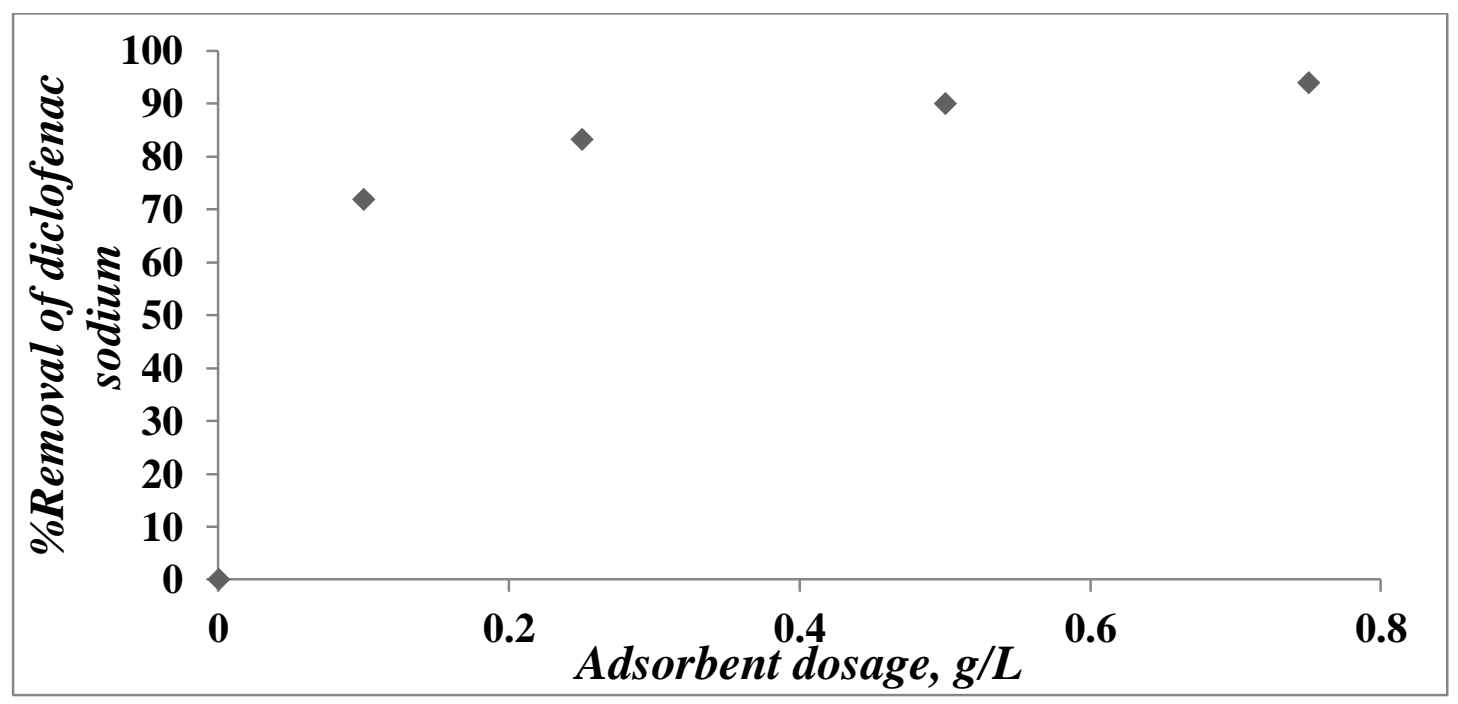

Fig. 8: Effect of Adsorbent amount on DCF removal by S-MC

( $\mathrm{pH}$ 2, room temperature, $60 \mathrm{~min}$, initial conc. $50 \mathrm{mg} / \mathrm{l})$.

\subsection{Effect of diclofenac sodium concentration}

The effect of the initial concentration of diclofenac sodium on the $\%$ removal at equilibrium is shown in Fig. 9. This figure shows that the increase of concentration decreases the percentage of DCF removal, by S-MC. As diclofenac sodium concentration increases from $20 \mathrm{mg} / \mathrm{l}$ to $70 \mathrm{mg} / \mathrm{l}$, the percentage removal was decrease from $81.66 \%$ to

$34.67 \%$ for S-MC adsorbent. 


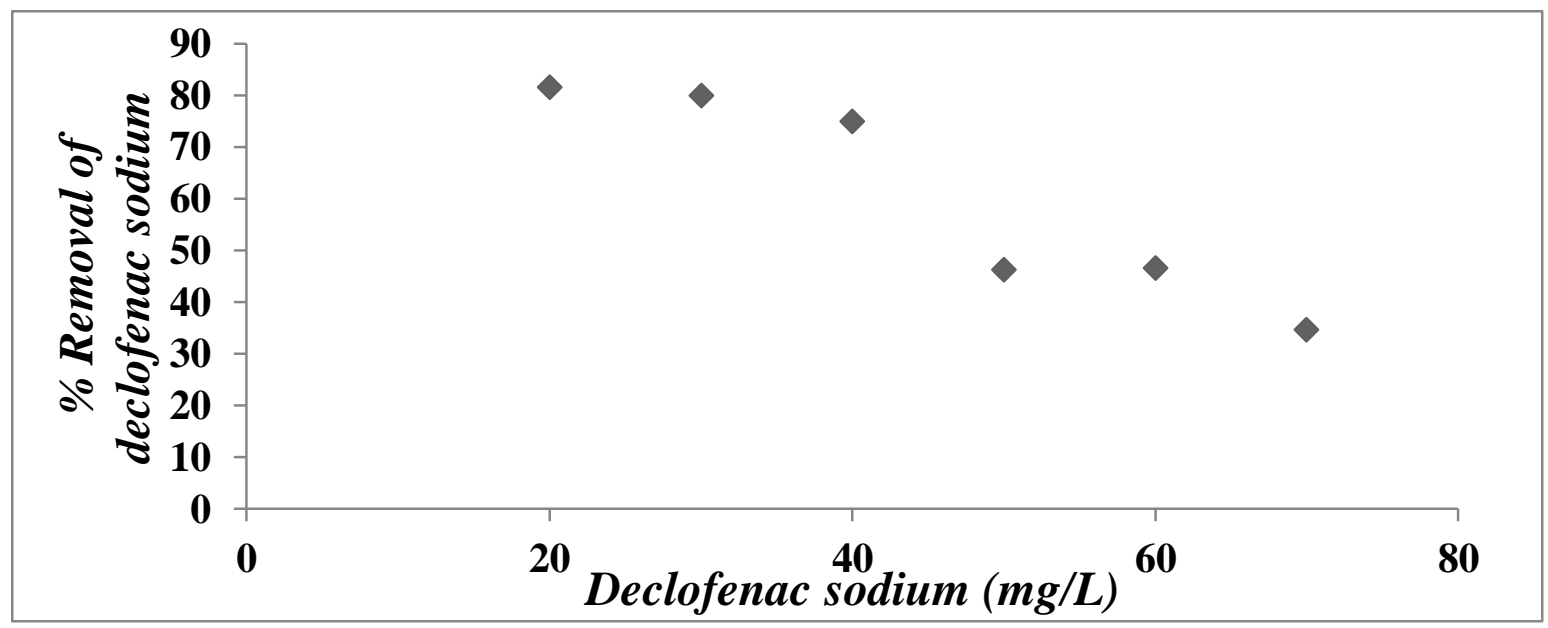

Fig. 9: Effect of concentration on DCF removal by S-MC ( $\mathrm{pH} 2$, room temperature, $60 \mathrm{~min}$, adsorbent amount $0.5 \mathrm{~g} / \mathrm{l}$ ).

\section{8. Adsorption kinetics}

In order to examine the influence of contact time on the adsorption capacity, adsorption experiments were carried out at different time intervals while holding the other process parameters constant at their optimum values $(\mathrm{pH} \sim 2$, adsorbent dosage at $0.5 \mathrm{~g} / \mathrm{l}$ and DCF initial concentration at $50 \mathrm{mg} / \mathrm{l})$. As shown in Fig. 5, the adsorption capacity of DCF onto $\mathbf{S}$ MC increased swiftly in the first $20 \mathrm{~min}$ and thereafter, it continued to increase, however, at a lower rate, till it reached an equilibrium state at $60 \mathrm{~min}$. In view of these results, all the succeeding adsorption experiments were conducted with a contact time of $60 \mathrm{~min}$ to assure that the adsorption equilibrium was indeed achieved.

Table 2 : Fitted parameters of DCF adsorption kinetics on S-MC

\begin{tabular}{|l|l|l|l|l|l|}
\hline \multicolumn{3}{|l|}{ Pseudo-first-order model } & \multicolumn{3}{l|}{ Pseudo-second-order model } \\
\hline $\mathbf{R}^{\mathbf{2}}$ & $\mathbf{K}_{\mathbf{1}}$ & $\mathbf{q}_{\mathbf{e}}(\mathbf{m g} / \mathbf{g})$ & $\mathbf{R}^{\mathbf{2}}$ & $\mathbf{K}_{\mathbf{2}}$ & $\mathbf{q}_{\mathbf{e}}(\mathbf{m g} / \mathbf{g})$ \\
\hline 0.960 & 0.0496 & 590.222 & 0.994 & 0.0001301 & 909.09 \\
\hline
\end{tabular}

In order to grasp more insight about the adsorption rate and adsorption kinetics was also studied and discussed. Herein, pseudo-first-order (Eq. (4)) and pseudo-second-order (Eq. (5)) 
kinetic models were employed to model the kinetic adsorption data of DCF on S-MC.

$$
\begin{aligned}
& \ln \left(q_{e}-q_{t}\right)=\ln q_{e}-k_{1} t \\
& \frac{t}{q_{t}}=\frac{1}{k_{2}\left(q_{e}\right)^{2}}-\frac{t}{q_{e}}
\end{aligned}
$$

Where $\mathrm{k}_{1}\left(\mathrm{~min}^{-1}\right)$ and $\mathrm{k}_{2}(\mathrm{~g} / \mathrm{mg} / \mathrm{min})$ are the equilibrium rate constants of pseudo-first- and pseudo-second-order rate equation, respectively.

The values of the kinetic constants for the pseudo-first-order and the pseudo-second-order kinetic models were estimated from the straight graphs of $\ln \left(\mathrm{q}_{\mathrm{e}}-\mathrm{q}_{\mathrm{t}}\right)$ vs $\mathrm{t}$ (Fig. 10a) and $\mathrm{t} / \mathrm{q}_{\mathrm{t}} \mathrm{vs}$ t (Fig. 10b), respectively, and are compiled in Table 2 together with the corresponding correlation coefficient $\left(\mathrm{R}^{2}\right)$. An extremely high $\mathrm{R}^{2}$ value near to unity was obtained for the pseudo-second order kinetic model and they found that the highest value of qe was approximately $909.09 \mathrm{mg} \mathrm{g}^{-1}$, signifying that pseudo-second-order kinetic model was the optimum kinetic model to represent DCF adsorption by S-MC. The suitability of this kinetic model suggested that the removal rate of DCF was primarily ruled by a chemisorption step [38].

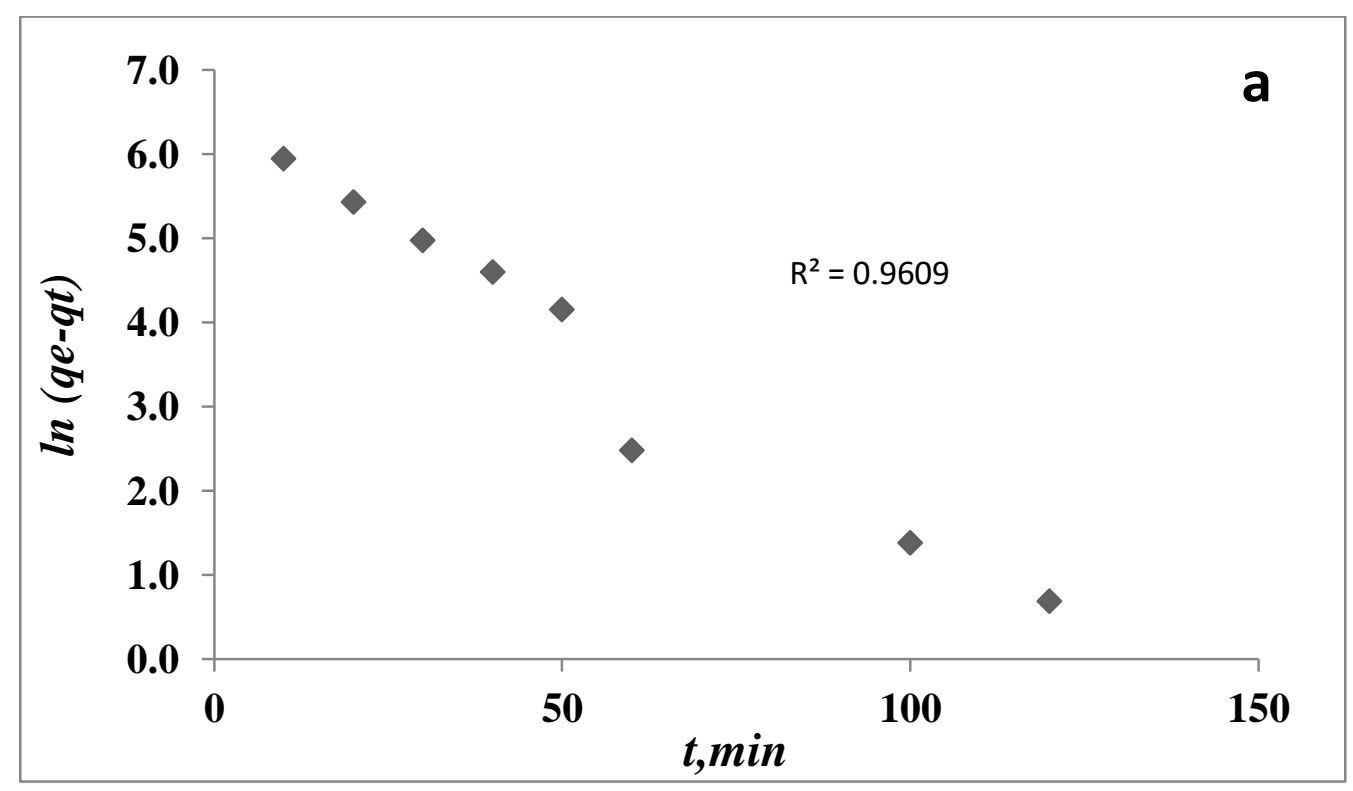




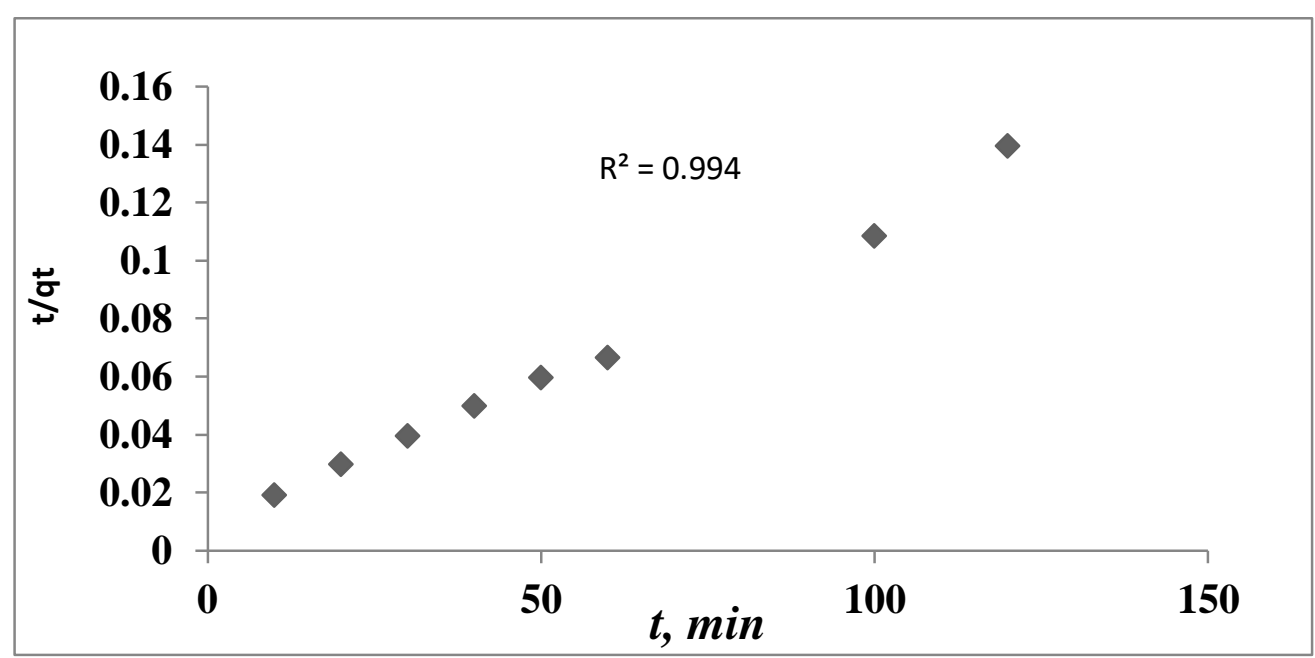

Fig. 10. Pseudo-first-order (a) and Pseudo-second-order

(b) linear plots for the removal of DCF onto S-MC.

\section{9. Adsorption isotherms}

In this study, Langmuir and Freundlich isotherm models were used to describe the adsorption isotherm and to study the relationship between the amounts of diclofenac sodium adsorbed $\left(\mathrm{q}_{\mathrm{e}}\right)$ and its equilibrium concentration in solution at $25^{\circ} \mathrm{C}$ as shown in Figs. 11, 12. The adsorption isotherm parameters, which were calculated from the slope and intercept of the linear plots using the linear form of the Langmuir and Freundlich equations, together with the determination coefficient $\mathrm{R}^{2}$ values are given in Table 3 . It is clear from the $\mathrm{R}^{2}$ values that the Langmuir isotherm is fitted to the experimental data more than the Freundlich isotherm model. The Langmuir isotherm shows that adsorption will increase with increasing diclofenac sodium concentration and this adsorption occurred in a multilayered system rather one layered.

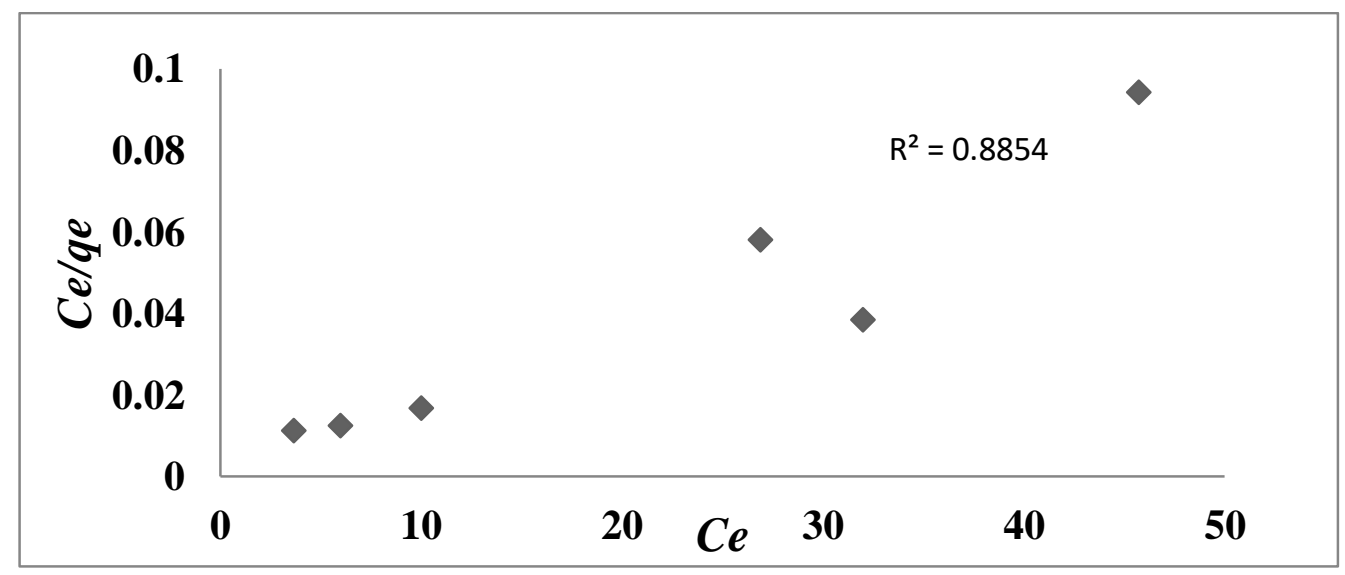

Fig. 11. Langmuir isotherm plots for DCF adsorption over S-MC. 


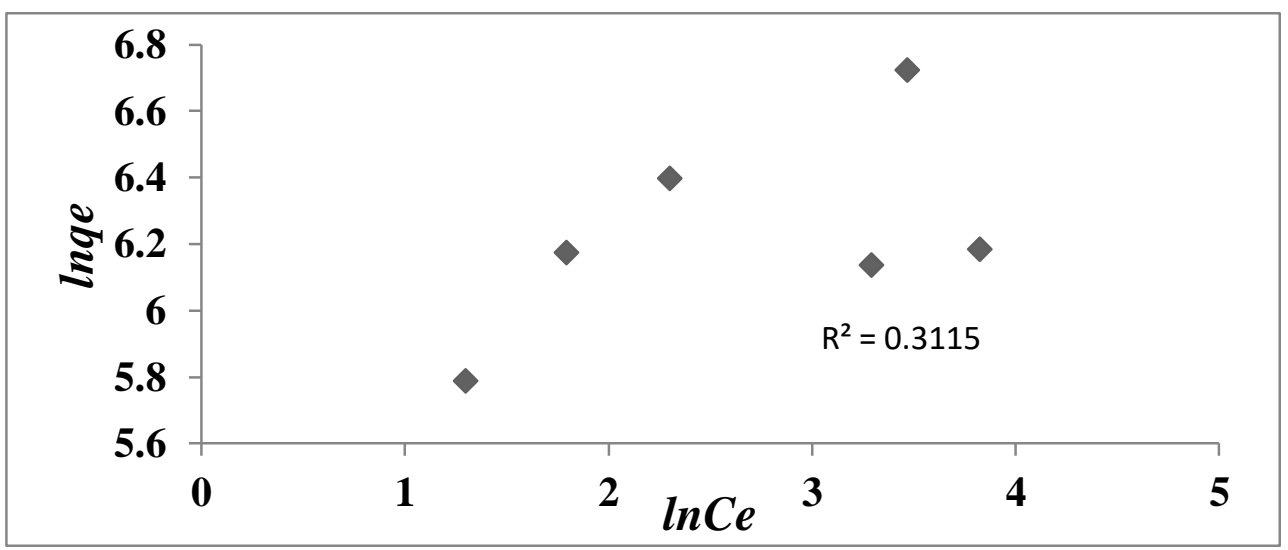

Fig. 12. Freundlich isotherm plots for DCF adsorption over S-MC

Table 3 : Parameters of Langmuir and Freundlich isotherms of DCF adsorption on S-MC

\begin{tabular}{|l|l|l|l|l|l|}
\hline \multicolumn{2}{|l|}{ Langmuir isotherm } & \multicolumn{3}{l|}{ Freundlich isotherm } \\
\hline $\mathbf{R}^{\mathbf{2}}$ & $\mathbf{K}_{\mathbf{L}}(\mathbf{l} / \mathbf{m g})$ & qmax $(\mathbf{m g} / \mathbf{g})$ & $\mathbf{R}^{\mathbf{2}}$ & $\mathbf{K}_{\mathbf{f}}$ & $\mathbf{N}$ \\
\hline 0.8854 & 3.6 & 555.56 & 0.3115 & 323.662 & 5.858 \\
\hline
\end{tabular}

\section{CONCLUSIONS}

Highly mesoporous carbons were prepared via the carbonization of biomass feedstocks (sucrose) with eutectic salt $(\mathrm{KCl} / \mathrm{ZnCl} 2(\mathrm{ES})$ ) as the porogen. $\mathrm{ES}$ played a crucial role in the formation of mesopores in the resultant carbon. In particular, the $\mathbf{S - M C}$ derived from sucrose via a gradient temperature program and sucrose to ES ratio of $1: 6$ showed a mesopore proportion of $70 \%$ and a BET $\mathrm{SSA}$ up to $575.5 \mathrm{~m}^{2} \mathrm{~g}^{-1}$. This work offers a simple way to prepare $\mathbf{S}-\mathbf{M C}$ from biomass, and the resultant $\mathbf{S}-\mathbf{M C}$ may have promising applications as a separation sorbent. Most of the studies like effect of contact time, concentration, $\mathrm{pH}$ and temperature gave good results which agreed with recent and previous studies. In the given conditions, more than $90.2 \%$ efficiency was achieved within 20 min of reaction. Finally pseudo second order describes the adsorption isotherm of DCF onto S-MC more efficiently than pseudo first order and the thermodynamic parameters indicated that the adsorption process was spontaneous. 


\section{REFERENCES}

[1] J. R .Holst, and A. I.Cooper, "Ultrahigh surface area in porous solids." Adv. Mater., 22(45):(2010) 5212-5216.

[2] M. Shiddiq, T.Ivandini and Y. Krisnandi,"Mesoporous carbon synthesis and its application for electrochemical capacitors. "( 2020) AIP Conference Proceedings, AIP Publ*89ishing LLC.,).

[3] L. Pikna, M. Heželová, S.Demčáková, M.Smrčová, B.Plešingerová, M.Štefanko, M .Turáková, M.Králik, P.Puliš, and P.Lehocký, "Effect of support on activity of palladium catalysts in nitrobenzene hydrogenation." Chem. Papers, 68(5): (2014) 591-598.

[4] X. Li, H.Zhu, C.Liu, P.Yuan, Z.Lin, J.Yang, Y.Yue, Bai Z., T.Wang , and X.Bao ,"Synthesis, modification, and application of hollow mesoporous carbon submicrospheres for adsorptive desulfurization." Ind. \& Eng. Chem. Res., 57(44): (2018) 15020-15030.

[5] B.Tiryaki, E.Yagmur, A. Banford, and Z.Aktas ,"Comparison of activated carbon produced from natural biomass and equivalent chemical compositions." J.Anal. and Appl. Pyrol,105: (2014) 276-283.

[6] E.Yagmur, M. S.Tunc, A.Banford ,and Z.Aktas, "Preparation of activated carbon from autohydrolysed mixed southern hardwood." J.Anal. and Appl. Pyrol.,104: (2013) 470-478.

[7] J.Zhou, A.Luo, and Y.Zhao, "Preparation and characterisation of activated carbon from waste tea by physical activation using steam." J. the Air \& Waste Manag. Assoc., 68(12): (2018) 12691277.

[8] N.Sych, S.Trofymenko, O.Poddubnaya, M. Tsyba, V.Sapsay, D.Klymchuk, and A.Puziy, "Porous structure and surface chemistry of phosphoric acid activated carbon from corncob." Appl. Surf. Sci., 261: (2012) 75-82.

[9] J.Wang, A.Heerwig, M. R. Lohe, M.Oschatz, L.Borchardt , and S.Kaskel ,"Fungi-based porous carbons for CO 2 adsorption and separation." J. Mater. Chem.,22(28): (2012)13911-13913.

[10] I. I. Gurten, M.Ozmak, E.Yagmur, and Z.Aktas ,"Preparation and characterisation of activated carbon from waste tea using K2CO3." Biomass and Bioenergy,37: (2012) 73-81.

[11] M.Divino, DA. Rocha, F.Pereira Dias Viegas, H.Cristina Campos, P.Carolina Nicastro, P.Calve Fossaluzza, C.Alberto Manssour Fraga, E. J. Barreiro and C.Viegas ,"The role of natural products in the discovery of new drug candidates for the treatment of neurodegenerative disorders II: Alzheimer's disease." CNS \& Neurological Disorders-Drug Targets (Formerly Current Drug Targets-CNS \& Neurological Disorders), 10(2): (2011) 251-270.

[12] M. Sevilla, A. B.Fuertes and. R.Mokaya, "High density hydrogen storage in superactivated carbons from hydrothermally carbonized renewable organic materials." Energy \& Environ. Sci., 4(4): (2011) 1400-1410.

[13] M. M.Alam, M. A.Hossain, M. D.Hossain, M. Johir, J.Hossen, M. S.Rahman, J. L.Zhou, A.Hasan, A. K.Karmakar and M. B.Ahmed ,"The potentiality of rice husk-derived activated carbon: From synthesis to application." Processes ,8(2): (2020)203. 
[14] M.Isik, H.Sardonand D.Mecerreyes ,"Ionic liquids and cellulose: dissolution, chemical modification and preparation of new cellulosic materials." Inter. j. molec. sci. ,15(7): (2014)1192211940.

[15] P.Maki-Arvela, T.Salmi, B.Holmbom, S.Willfor and D. Y.Murzin,"Synthesis of sugars by hydrolysis of hemicelluloses-a review." Chem. Reviews ,111(9): (2011)5638-5666.

[16] S.Shylesh, A. A.Gokhale, C. R. Ho and A. T.Bell, "Novel strategies for the production of fuels, lubricants, and chemicals from biomass." Accoun. chem. res.,50(10): (2017) 2589-2597.

[17] L. K.Shrestha, M.Thapa, R. G.Shrestha, S.Maji, R. R.Pradhananga and K.Ariga ,"Rice huskderived high surface area nanoporous carbon materials with excellent iodine and methylene blue adsorption properties." C_-J. Carbon Res. ,5(1): (2019) 10.

[18] T. P.Fellinger, R. J. White, M. M.Titirici and M.Antonietti, "Borax-mediated formation of carbon aerogels from glucose." Adv. Functional Mater., 22(15): (2012) 3254-3260.

[19] D.Saha, Y.Li, Z.Bi, J.Chen, J. K.Keum, D. K. Hensley, H H. Grappe, M. A.Meyer III, S.Dai and M. P.Paranthaman, "Studies on supercapacitor electrode material from activated ligninderived mesoporous carbon." Langmuir, 30(3): (2014) 900-910.

[20] M.Antonietti, N.Fechler and T.-P.Fellinger ,"Carbon aerogels and monoliths: control of porosity and nanoarchitecture via sol-gel routes." Chem. Mater. ,26(1): (2014)196-210.

[21] X.Gao, L.Wu, Z.Li, Q.Xu, W.Tian and. R.Wang,"Preparation and characterization of high surface area activated carbon from pine wood sawdust by fast activation with H 3 PO 4 in a spouted bed." J. Mater. Cycles and Waste Manag. ,20(2): (2018) 925-936.

[22] A. S.Mestre, R. A.Pires, I.Aroso, E. M. Fernandes, M. L.Pinto, R. L.Reis, M. A.Andrade, J.Pires, S. P.Silva and A. P.Carvalho, "Activated carbons prepared from industrial pre-treated cork: Sustainable adsorbents for pharmaceutical compounds removal." Chem. Eng. J., 253: (2014) 408-417.

[23] M. Sevilla, A.Fuertes and R.Mokaya ,"Preparation and hydrogen storage capacity of highly porous activated carbon materials derived from polythiophene." Internat. j. hydrogen energy, 36(24): (2011) 15658-15663.

[24] X.Song, Y.Zhang and C.Chang, "Novel method for preparing activated carbons with high specific surface area from rice husk." Ind. \& eng. chem. res.,51(46): (2012)15075-15081.

[25] Y.Xiao, H.Chen, M. Zheng, H.Dong, B.Lei and Y.Liu, "Porous carbon with ultrahigh specific surface area derived from biomass rice hull." Mater. Letters, 116: (2014) 185-187.

[26] N.Fechler, T. P.Fellinger and M.Antonietti, "'Salt templating": a simple and sustainable pathway toward highly porous functional carbons from ionic liquids." Adv. Mater.,25(1): (2013)75-79.

[27] N.Fechler, S.-A.Wohlgemuth, P.Jäkerand. M.Antonietti ,"Salt and sugar: direct synthesis of high surface area carbon materials at low temperatures via hydrothermal carbonization of glucose under hypersaline conditions." J. Mater. Chem. A 1 ,(33): (2013)9418-9421. 
[28] T.Pagketanang, A.Artnaseaw, P.Wongwicha and M.Thabuot ,"Microporous activated carbon from $\mathrm{KOH}$-activation of rubber seed-shells for application in capacitor electrode." Energy Procedia, 79(2015): (2015) 651-656.

[29] J.Kaźmierczak, P.Nowicki and. R.Pietrzak ,"Sorption properties of activated carbons obtained from corn cobs by chemical and physical activation." Adsorp., 19(2-4): (2013)273-281.

[30] B. K .Hamad, "Preparation and characterization of activated carbon from oil palm shell activated by KOH." J. Pure Appl. Sci, 27: (2015) 27-38.

[31] N.Dejang, O.Somprasit and S.Chindaruksa, "A preparation of activated carbon from Macadamia shell by microwave irradiation activation." Energy Procedia, 79: (2015) 727-732.

[32] J. N .Nsami, and J. K.Mbadcam ,"The Adsorption Efficiency of Chemically Prepared Activated Carbon from Cola Nut Shells by $\mathrm{ZnCl} 2$ on Methylene Blue." J. chem., (2013).

[33] X. Liu , and M.Antonietti ,"Molten salt activation for synthesis of porous carbon nanostructures and carbon sheets." Carbon, 69: (2014)460-466.

[34] X.Liu, N.Fechler and M.Antonietti ,"Salt melt synthesis of ceramics, semiconductors and carbon nanostructures." Chem. Soc. Reviews,42(21): (2013) 8237-8265.

[35] X.Liu, C.Giordano and M.Antonietti, "A Facile Molten-Salt Route to Graphene Synthesis." Small, 10(1): (2014)193-200.

[36] R.Ruiz Rosas, F. J.García-Mateos, M. d. C.Gutiérrez, J.Rodríguez-Mirasoland T. Cordero , About the Role of Porosity and Surface Chemistry of Phosphorus-Containing Activated Carbons in the Removal of Micropollutants." Frontiers in Mater. ,6: (2019)134.

[37] J. N. Nsami, and J. K.Mbadcam ,"The Adsorption Efficiency of Chemically Prepared Activated Carbon from Cola Nut Shells by $\mathrm{ZnCl} 2$ on Methylene Blue." J. chem., (2013).

[38] D.Lin, Y.Huang, Y.Yang, X.Long, W.Qin, H.Chen, Q. Zhang, Z. Wu, S.Li and D.Wu,"Preparation and Characterization of Highly Ordered Mercapto-Modified Bridged Silsesquioxane for Removing Ammonia-Nitrogen from Water." Polymers ,10(8): (2018) 819.

[39] S.Zhang, M.Zheng, Z.Lin, N.Li, Y.Liu, B.Zhao, H.Pang, J.Cao, P.He and Y.Shi, "Activated carbon with ultrahigh specific surface area synthesized from natural plant material for lithiumsulfur batteries." J. Mater. Chem., A 2(38): (2014) 15889-15896. 


$$
\begin{aligned}
& \text { الملخص العربي } \\
& \text { تحضير ونوصيف كربون وسطي المسام من مصادر مختلفه واستعماله في امتز از مركب ديكلوفينالك من محاليل مائيه } \\
& \text { ابتسام سعيد حمزه , ناديه عبدالحكيم يوسف, سهام علي شعبان } \\
& \text { كليه البنات جامعه عين شمس , كليه البنات جامعه عين شمس , معهد بحوث البترول }
\end{aligned}
$$

تم استخدام المو اد التركيبية للكربون متوسط المسام من الكتلة الحيوية بما في ذلك السكروز كمورد للكربون ، وتم استخدام الملح سهل الانصهار كعامل بوروجين لتحضير (كربونات السكروز منوسطة المسام) تم فحص العينات الناتجة عن طريق تقنيات مختلفة ، بما في ذللك التحليل الحراري و FTIR و الميكروسكوب الالكتروني, حيود الأشعة السينية ,وقياسات

تحقق من فعالية امتصاص الديكلوفينالك بواسطة الكربون عالي المسام باستخدام التحليل الطيفي المرئي فوق البنفسجي. نم قياس التركيزات النهائية للايكلوفيناك باستخدام التحليل الطيفي فوق البنفسي المرئي في ظروف مختلفة (الاس الهيدروجيني ، وقت التلامس ، درجة الحرارة ، وزن عامل الادمصاص، وزن الماده المدمصة . 